\title{
Investigation of the Pulsed Annular Gas Jet for Chemical Reactor Cleaning
}

\author{
Zvegintsev Valery Ivanovich, Nalivaichenko Denis Gennadievich, \\ and Chirkashenko Vladimir Fedorovich
}

\author{
Khristianovich Institute of Theoretical and Applied Mechanics, Siberian Branch, Russian Academy of Sciences, \\ Novosibirsk 630090, Russia \\ Correspondence should be addressed to Zvegintsev Valery Ivanovich, zvegin@itam.nsc.ru
}

Received 29 February 2012; Revised 29 April 2012; Accepted 24 May 2012

Academic Editor: Shaliza Binti Ibrahim

Copyright (C 2012 Zvegintsev Valery Ivanovich et al. This is an open access article distributed under the Creative Commons Attribution License, which permits unrestricted use, distribution, and reproduction in any medium, provided the original work is properly cited.

\begin{abstract}
The most economical technology for production of titanium dioxide pigment is plasma-chemical syntheses with the heating of the oxygen. The highlight of the given reaction is formation of a solid phase as a result of interactions between two gases, thus brings the formation of particle deposits on the reactor walls, and to disturbing the normal operation of the technological process. For the solving of the task of reactor internal walls cleaning the pulsed gaseous system was suggested and investigated, which throws circular oxygen jet along surfaces through regular intervals. Study of aerodynamic efficiency of the impulse system was carried by numerical modeling and experimentally with the help of a specially created experimental facility. The distribution of the pulsed flow velocity at the exit of cylindrical reactor was measured. The experimental results have shown that used impulse device creates a pulsed jet with high value of the specified flow rate. It allows to get high velocities that are sufficient for the particle deposits destruction and their removal away. Designed pulsed peelings system has shown high efficiency and reliability in functioning that allows us to recommend it for wide spreading in chemical industry.
\end{abstract}

\section{Introduction}

The most technologically advanced and economical method of production of titanium dioxide pigment is a plasmachemical synthesis of oxygen with heating to $3500 \mathrm{~K}$ in an arc plasma torch [1-3]. In this process, titanium dioxide is formed by the oxidation of atomized liquid titanium tetrachloride, which interacts with an oxygen plasma. Chemical reactor, which implements the technology in question, represents a cylindrical tube with an inner diameter of 200$300 \mathrm{~mm}$ and a length of $1,000-2,000 \mathrm{~mm}$. At the entrance to the reactor, a torch is installed, which creates a high subsonic jet of oxygen and feeder tetrachloride into the jet. At the reactor outlet, gas stream is obtained with particles of titanium dioxide, which are separated in a certain way from the gas phase.

A feature of this reaction is the formation of a solid phase as a result of the interaction of two gaseous components.
Originally appearing particles of titanium dioxide are in gaseous state, then the condensation of the moleculardispersed titanium dioxide formed aerosols. As the particles pass the reactor space as their size increases due to condensation of titanium dioxide from the gas phase on the particle surface and by coalescence of individual particles into larger agglomerates, resulting in particle sizes reach $0.1-$ 0.4 microns. This raises the problem of sticking of particles on water-cooled walls of the reactor [4]. Buildup begins at $150-200 \mathrm{~mm}$ from the place of tetrachloride supply. The resulting scull can completely fill the workspace of the reactor and disrupt the process. Cleaning the inside surface of the reactor from the sticky particles by stationary slit jet of oxygen was recognized ineffective because of the low speed jet.

To ensure that effective cleaning is necessary to significantly increase the speed of the flow near the wall of the reactor. This problem can be solved by using a pulsed 


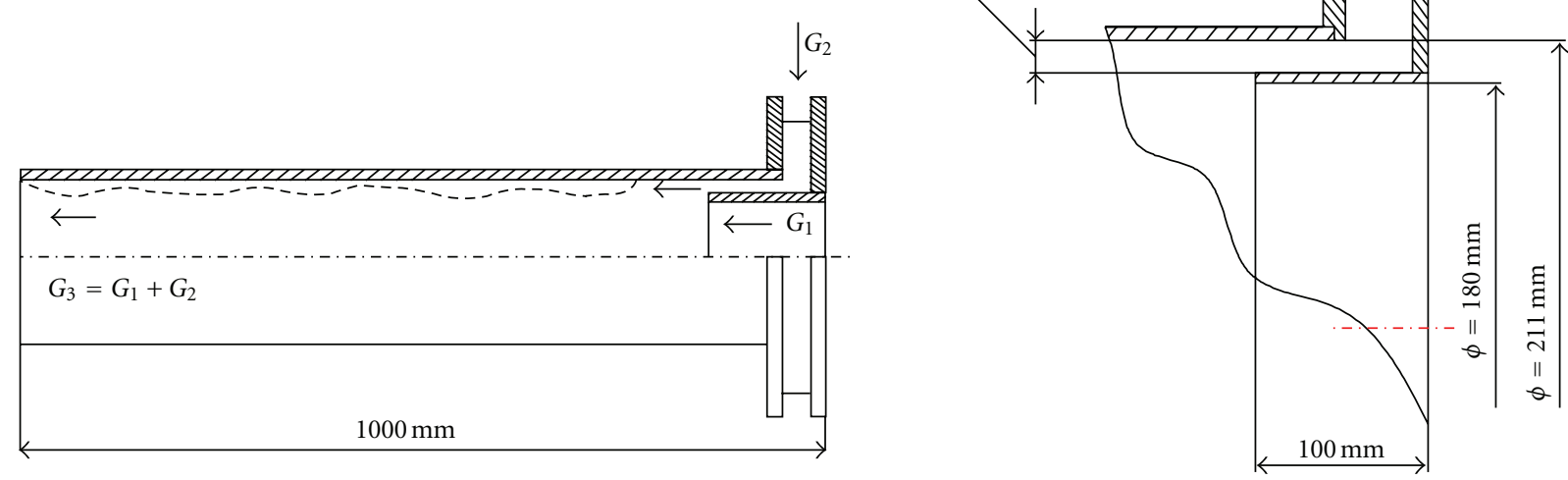

FIGURE 1: Proposed scheme of pulse cleaning system.

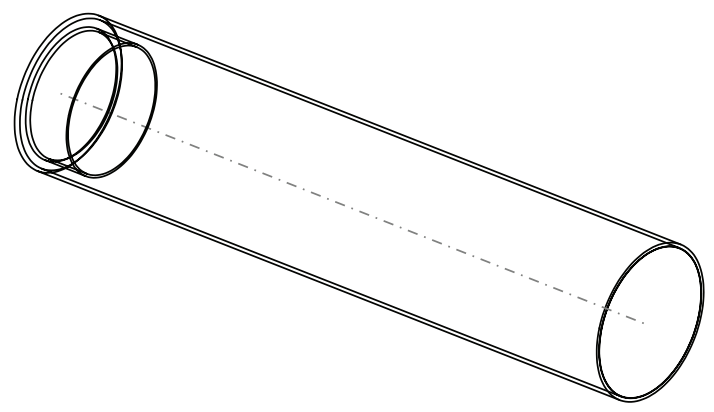

FIgURE 2: Scheme of the reactor with open entrance.

annular gas jet, which is released periodically along the inner wall of the reactor in the direction of flow [5-8]. Pulse mode provides the highest value of specific flow rate and, accordingly, the highest value of flow velocity. In addition, annular jet configuration provides displacement of the velocity maximum near the surface being cleaned. The proposed scheme of pulse cleaning system is shown in Figure 1.

In the central part, as before, continuously operating high-flow oxygen is fed together with a mixture of titanium tetrachloride. Consumption of gas components at the entrance $G_{1}$. With the help of a special ring around the inner wall of the reactor, periodically pulsed jet of oxygen is supplied at room temperature with high pressure. Flow rate of this jet will denote as $G_{2}$. The jet should create such a flow in the channel of the reactor, which breaks and removes the accumulating deposits on the reactor walls. It is natural that during the time of the pulsed jet creating the flow rate of the gas phase at the reactor outlet $G_{3}$ is the sum of flow rates of incoming gases $G_{1}$ and $G_{2}$.

From the technological conditions, the next additional requirements to the cleaning system follow. Produced gaseous jet should have a sufficiently high speed $(20-40 \mathrm{~m} / \mathrm{s})$ needed for deposit breaking, and a small total flow rate (not more than $10 \%$ of the basic flow of oxygen through the reactor). In the process of pulse jet forming, a pressure in the flow at the inlet of the reactor should not be increased,

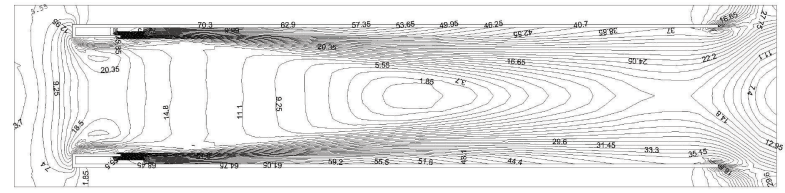

(a)

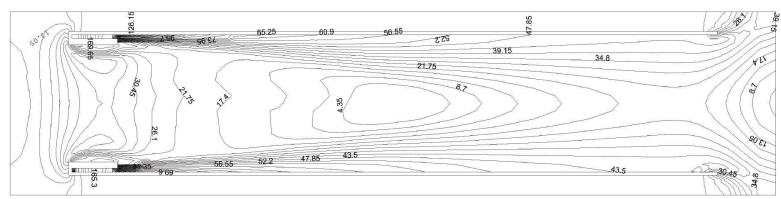

(b)

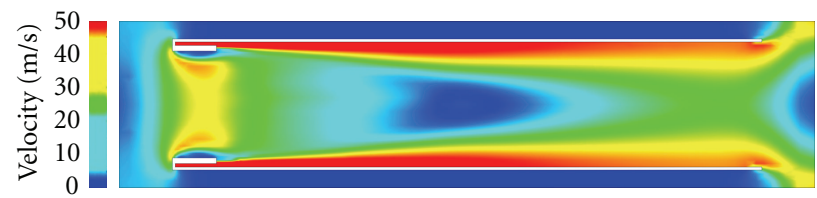

(c)

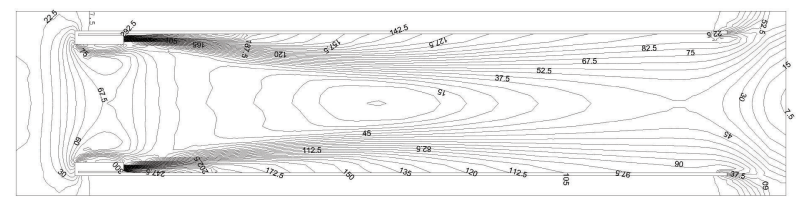

(d)

Figure 3: Isolines of the velocity $V$. (a) $\delta=12 \mathrm{~mm}$; (b) $\delta=6 \mathrm{~mm}$; (c) $\delta=6 \mathrm{~mm}$; (d) $\delta=2.5 \mathrm{~mm}$.

to avoid disruption of the arc plasma torch. In addition, a device for creating a pulsed jet should be simple in design and reliable in operation.

\section{Mathematical Model and Numerical Simulation Results}

Gas dynamics of flow in the reactor at different variants of the annular jet and entraining conditions at the inlet was studied 


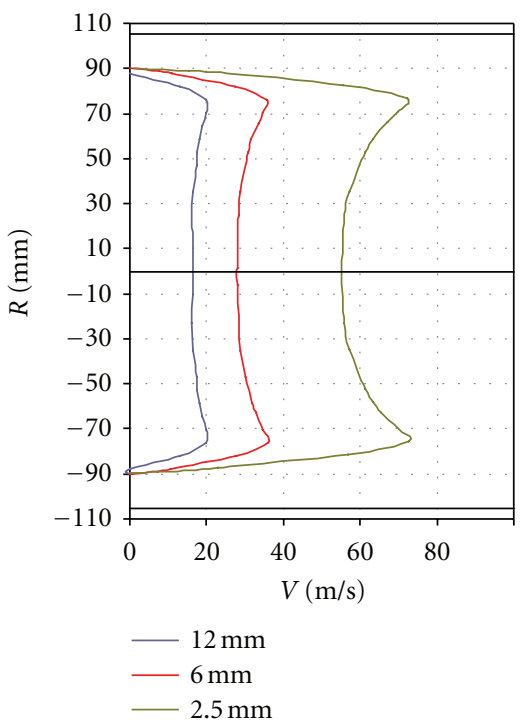

(a)

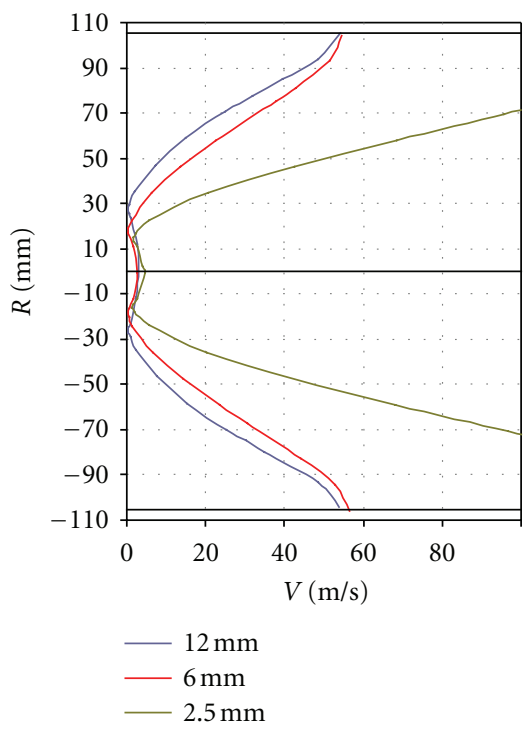

(b)

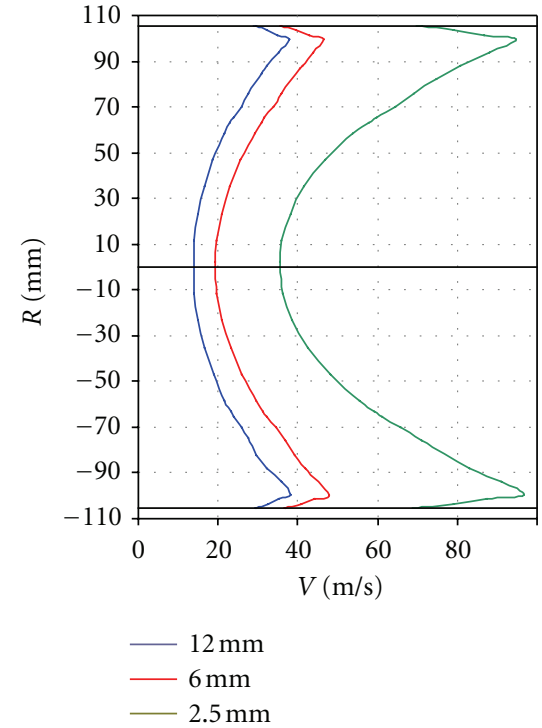

(c)

FIgURE 4: The velocity $V$. distribution in the cross-sections $(X=2 \mathrm{~mm}, 500 \mathrm{~mm}$, and $1000 \mathrm{~mm})$.

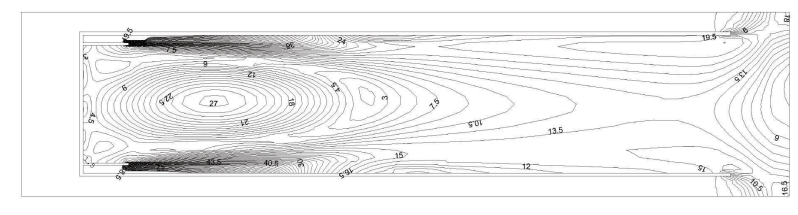

(a)

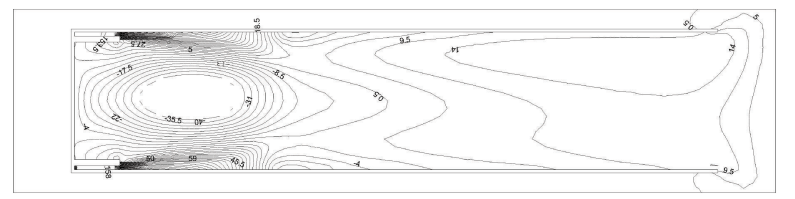

(c)

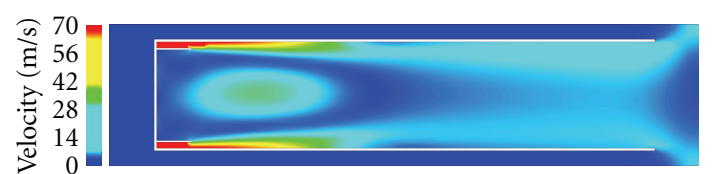

(b)

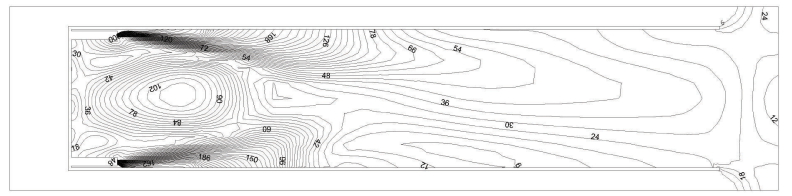

(d)

Figure 5: Isolines of the velocity $V$. (a) $\delta=12 \mathrm{~mm}$; (b) $\delta=12 \mathrm{~mm}$; (c) $\delta=6 \mathrm{~mm}$; (d) $\delta=2.5 \mathrm{~mm}$.

primarily by theoretical analysis [9] and then by means of numerical simulations. Calculations were performed using an integrated software package SolidWorks + ANSYS. Preparation of a geometric 3D model of the reactor was carried out in the program SolidWorks, then the model was imported in the computer module ANSYS, where the gas-dynamic calculations were performed. The specified computer software involves finite-volume method and timedependent Navier-Stokes equations for computations. The program automatically analyzes the body geometry and forms the computational grid on the surface of the body and released into the field of computing. In the process of solving, the grid was optimized in the areas of large flow parameter gradients.

The configuration of the calculated cases determined by the following terms and conditions. The hole diameter of $180 \mathrm{~mm}$ at the entrance of the reactor is opened or closed. The initial conditions in the reactor corresponded to ambient conditions. We considered three values of the height of the annular slot for gas injection: $2.5 \mathrm{~mm}, 6 \mathrm{~mm}$, and $12 \mathrm{~mm}$. In all cases, the flow rate of the annular jet remained constant with the value of $0.7 \mathrm{~kg} / \mathrm{s}$. Produced annular jet was either parallel to the axis of the reactor, or twisted in the tangential direction.

2.1. Entrance Is Opened: The Jet Is Parallel to the Axis. The scheme is shown in Figure 2. Figure 3 shows a typical velocity distribution inside the reactor under consideration at different heights ejecting slit. Figure 4 shows a comparison of the diagrams of velocities in the cross-sections at a distance of $2 \mathrm{~mm}, 500 \mathrm{~mm}$, and $1000 \mathrm{~mm}$ from the entrance.

As seen from Figure 3 in the considered range of slot heights, an annular jet injects air through the open entrance and expands in the propagation through the channel. The region of conical shape is formed inside the channel. The velocity in this region decreases from a maximum at the 


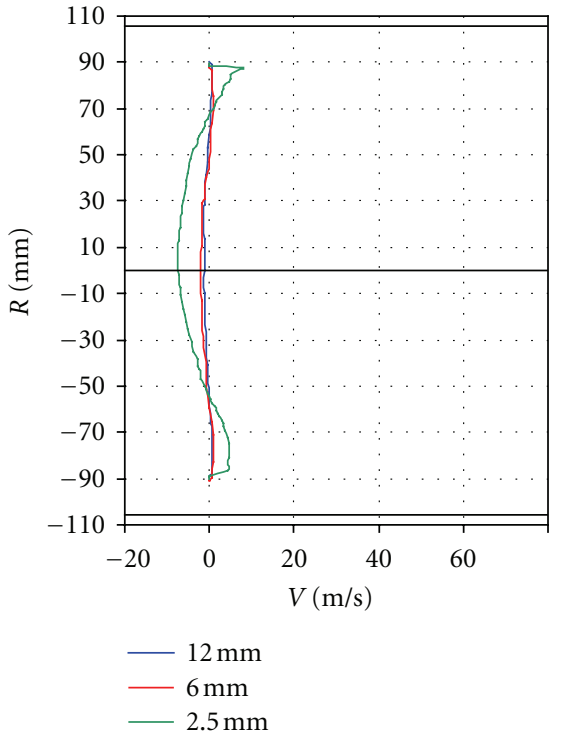

(a)

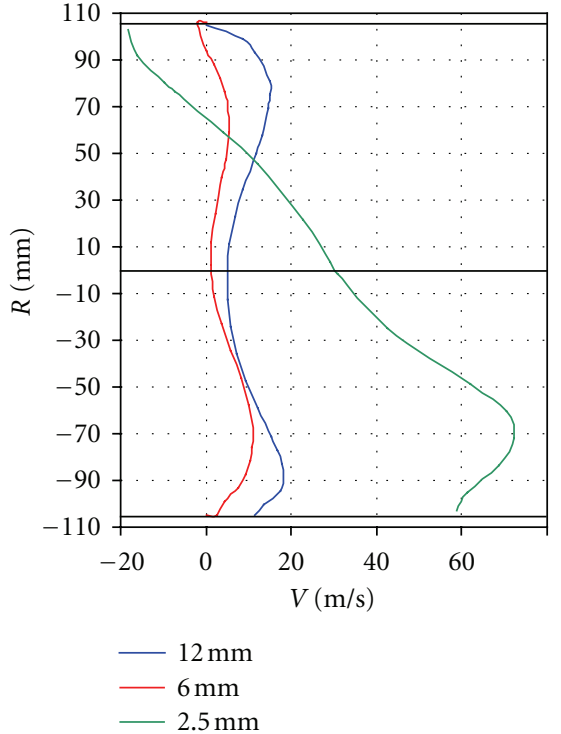

(b)

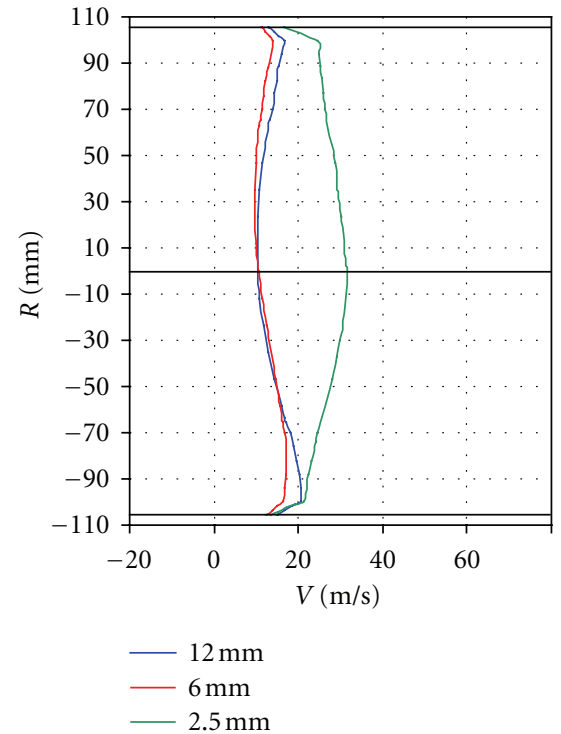

(c)

Figure 6: The velocity $V$ distribution in the cross-sections $(X=2 \mathrm{~mm}, 500 \mathrm{~mm}$, and $1000 \mathrm{~mm})$.

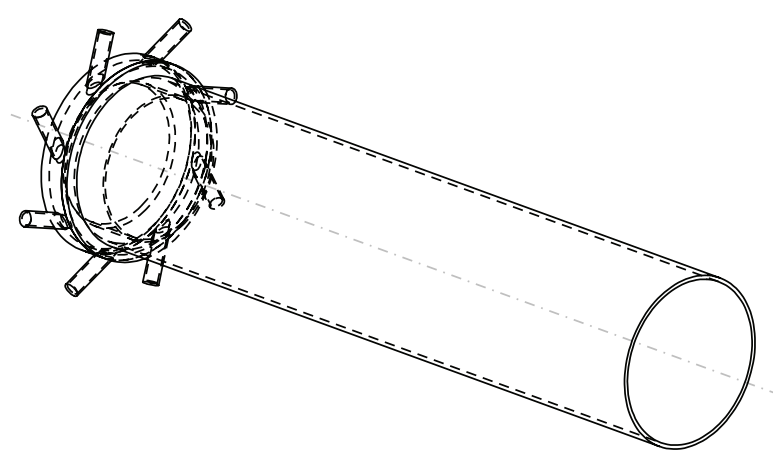

FIGURE 7: Scheme of the reactor with swirling ejecting jet.

entrance to almost zero in the middle of the channel. From these data, it is seen that the greatest velocity at the reactor walls creates a jet with a height of $2.5 \mathrm{~mm}$ slit (see Figure 4). This means that a maximum possible value of the dynamic pressure acts on deposits along the walls, which is required to accomplish the cleanup task.

2.2. Entrance Is Closed: The Jet Is Parallel to the Axis. The results of calculations of gas-dynamic parameters in the reactor with a closed entrance showed significant timedependent nature of the flow. In these calculations, we could not get a picture of the stationary distribution of velocities and flow parameters inside the reactor. Therefore, the figures below show the unsteady random velocity distribution in different sections.

The data presented (see Figures 5 and 6) show that the recirculation zone with reduced pressure is formed due to the action of the annular jet in the channel near the closed entrance. Implemented asymmetric velocity distribution in

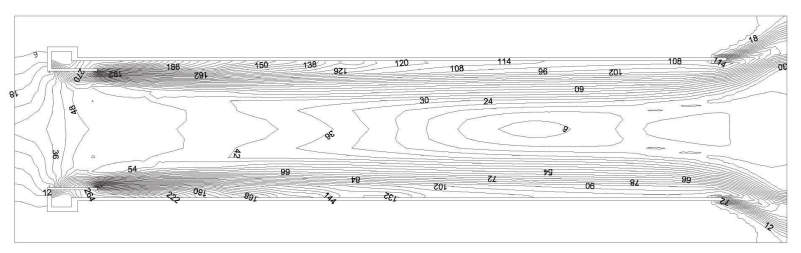

(a)

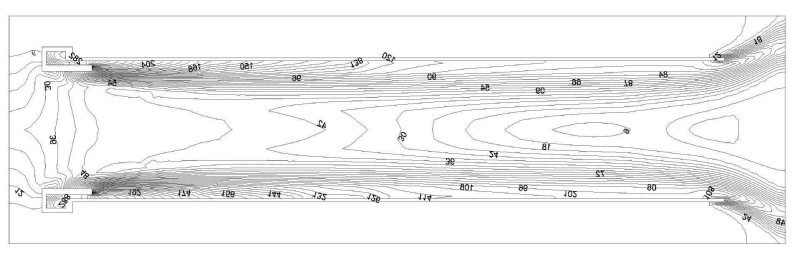

(b)

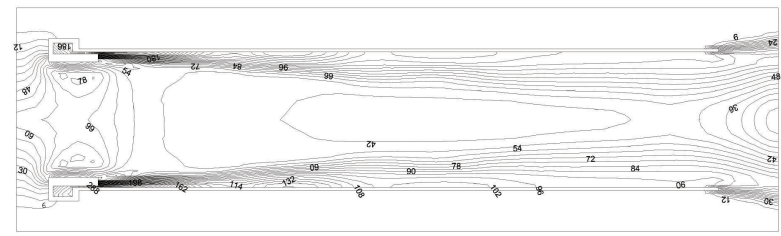

(c)

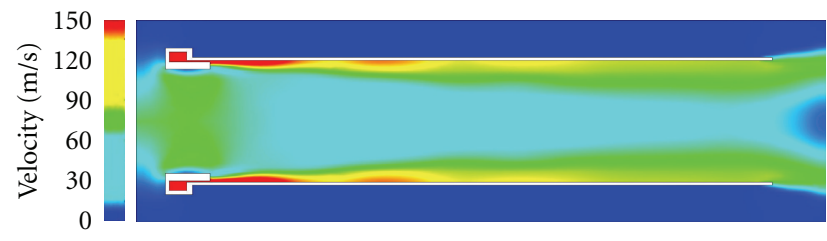

(d)

FIGURE 8: Isolines of the total velocity $V$. (a) $\delta=12 \mathrm{~mm}$; (b) $\delta=$ $6 \mathrm{~mm}$; (c) $\delta=2.5 \mathrm{~mm}$; (d) $\delta=2.5 \mathrm{~mm}$. 


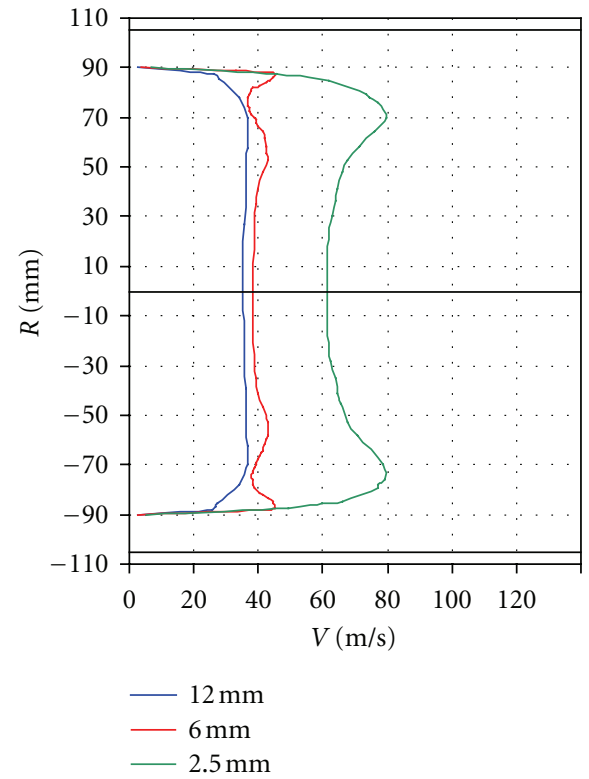

(a)

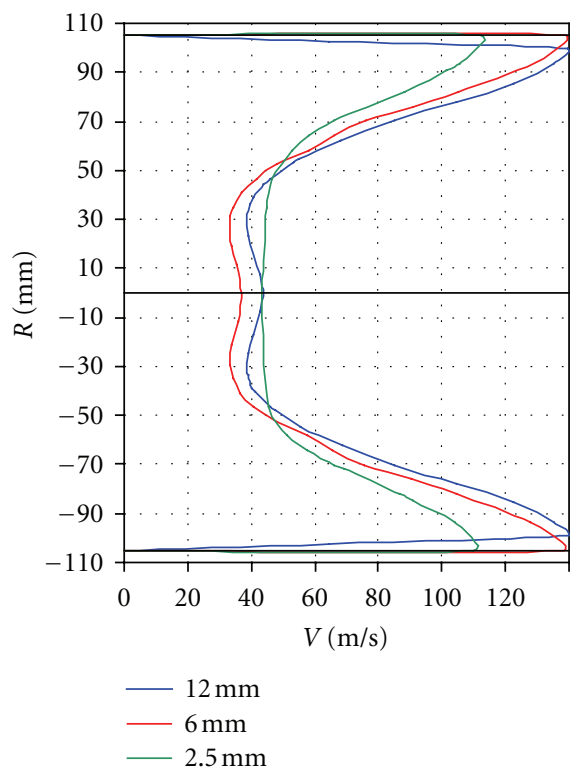

(b)

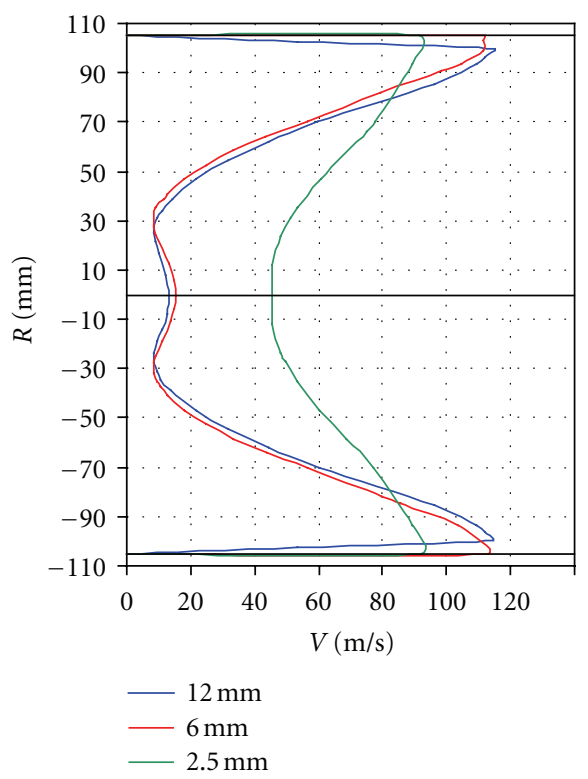

(c)

Figure 9: The total velocity $V$ distribution in the cross-sections $(X=2 \mathrm{~mm}, 500 \mathrm{~mm}$, and $1000 \mathrm{~mm})$.

the channel is explained by unsteady interaction of the recirculation zone with the annular jet.

The values of flow velocities in the annular jet inside the channel are substantially less than in the case of openchannel input. The main reasons of this situation are the low flow rate of ejected gas and the formation of low-pressure zone near to closed entrance.

2.3. Entrance Is Opened: Twisted Jet. The scheme is shown in Figure 7. The adopted computational technology allows us to calculate swirling flow in the channel of the reactor in the presence of the initial vorticity of ejecting jet. The typical distributions of the absolute values of velocity in the longitudinal and cross-sections are shown in Figures 8 and 9. It is seen that, at sufficiently high altitude the annular gap $(\delta=12 \mathrm{~mm}, 6 \mathrm{~mm})$, a decisive role in the jet parameters have dimensions of supplying pipes. With a decrease in the height of the slit, when its area becomes commensurate with the area of supplying pipes, the effect of vorticity the ejecting jet decreases, and the effect of the height of the annular gap on the parameters of the formed flow becomes crucial.

The data show that the swirling flow significantly affected the structure of the flow in the channel. Absolute flow velocity in the annular jet, and the inside of the channel 


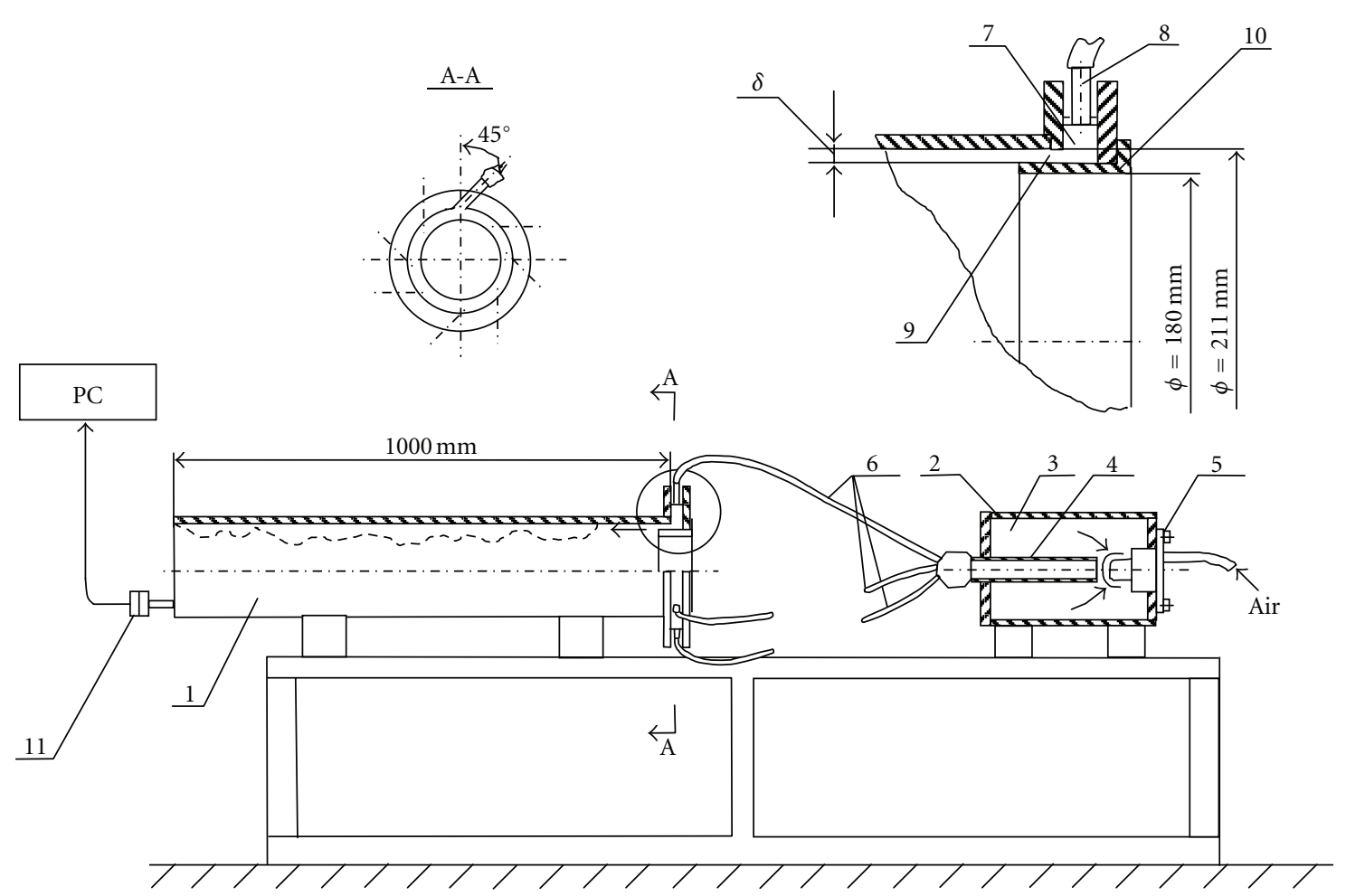

FIGURE 10: The experimental setup. (1) model of a chemical reactor, (2) pnevmopulse generator, (3) storage chamber, (4) exhaust nozzle, (5) high-speed valve, (6) rubber hose, (7) circular prechamber, (8) fitting, (9) slotted nozzle, (10) the input cylinder, and (11) total pressure probe.

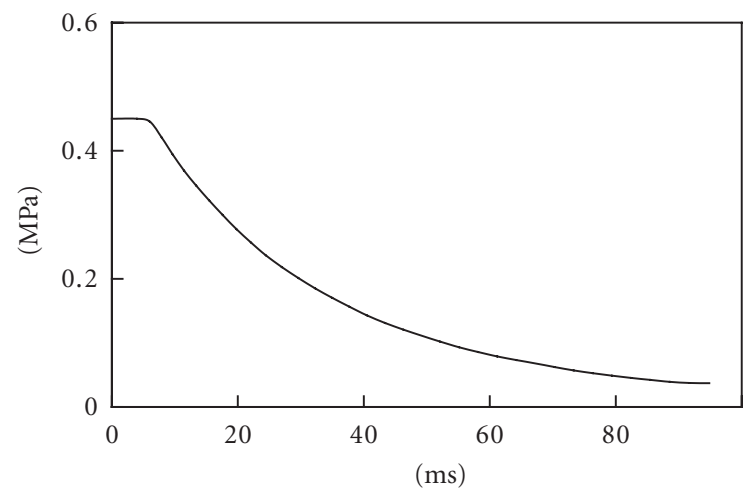

FIGURE 11: Total pressure of the air flow at the reactor entrance.

increased markedly relative to the situation with longitudinal blowing (see Figures 3 and 4). Inside the channel, in contrast to the longitudinal blowing, a uniform flow with velocity of $40 \mathrm{~m} / \mathrm{s}$ is forming almost at entire length.

Deceleration of the flow (up to $10 \mathrm{~m} / \mathrm{s}$ ) occurs only near the channel exit. It should be noted that the twisted blowing from the ring nozzle with a slit height of $2.5 \mathrm{~mm}$ leads to a decrease in flow velocity within the channel from $60 \mathrm{~m} / \mathrm{s}$ at the entrance up to $40 \mathrm{~m} / \mathrm{s}$ in the middle of the channel, and again increases at the outlet of the channel. At the same time, the flow velocity at the channel walls reaches $120 \mathrm{~m} / \mathrm{s}$. Typical peculiarities of vortex flow in velocity profiles in the

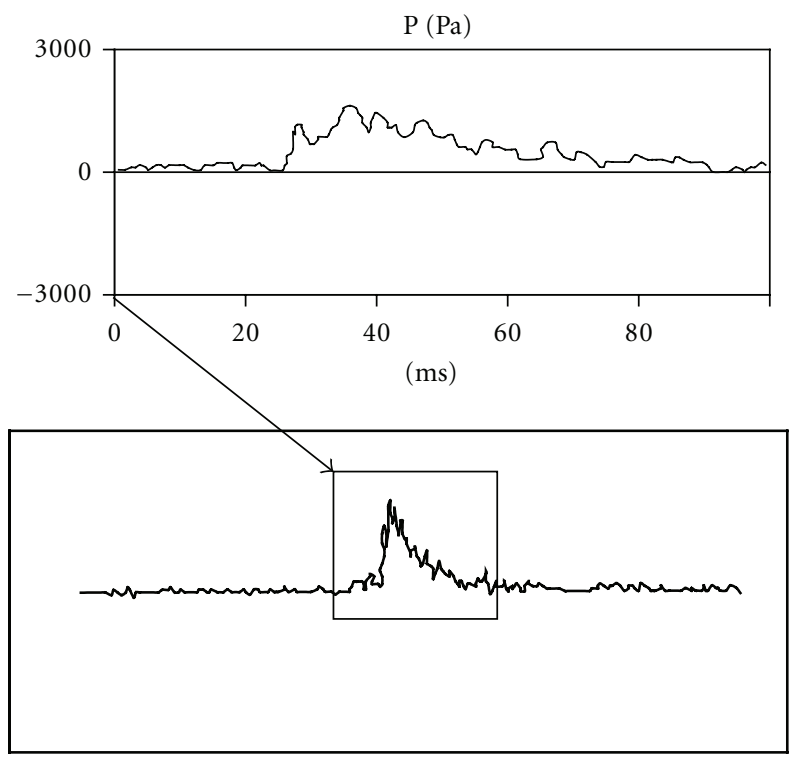

FIgURE 12: Total pressure of the air flow at the reactor exit.

transverse and longitudinal sections of the channel indicate that the twist flow is saved along the entire length of the channel. The increase in ejection of air with open entrance of the reactor caused by the intensification of the mixing process for swirling annular jet due to additional azimuthal velocity component. 


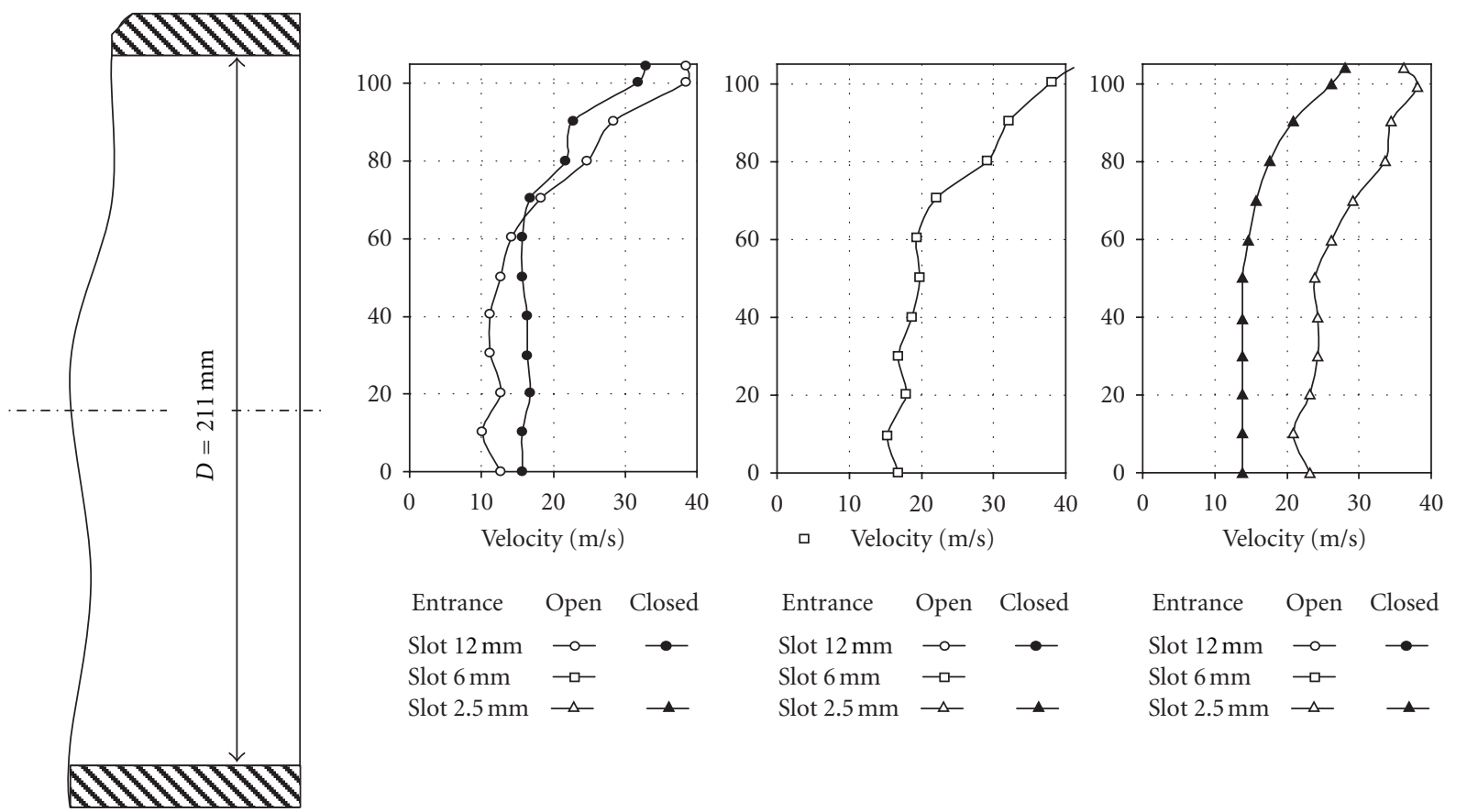

FIGURE 13: Distribution of mean velocity at the outlet of the reactor model.

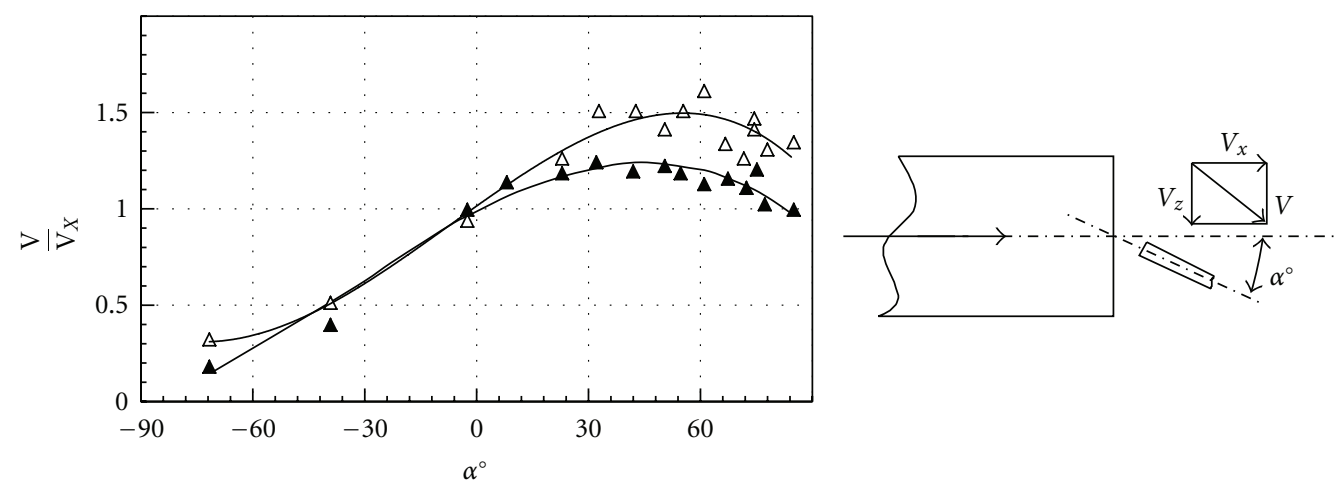

FIgURE 14: Measurement of twist angle of the annular jet (notation as in Figure 13).

TABLE 1: Experimental results.

\begin{tabular}{lcccc}
\hline & & $12 \mathrm{~mm}$ & $6 \mathrm{~mm}$ & $2.5 \mathrm{~mm}$ \\
\hline & Width of the annular gap & 0.92 & 1.07 & 1.23 \\
& Entrance is opened experiment & 1.19 & 1.61 & 2.51 \\
Mass flow rate at the outlet, $\mathrm{kg} / \mathrm{s}$ & Entrance is opened calculations & 0.87 & - & 0.73 \\
& Entrance is closed experiment & 0.70 & 0.70 & 0.70 \\
& Entrance is closed calculations & 1.62 & 1.52 & 2.83 \\
\hline & Entrance is opened swirling jet calculations & 0.35 & 0.57 & 0.81 \\
& Entrance is opened experiment & 0.75 & 1.37 & 2.69 \\
Ejection coefficient $\left(G_{3}-G_{1}\right) / G_{1}$ & Entrance is opened calculations & 0.28 & - & 0.07 \\
& Entrance is closed experiment & 0.00 & 0.00 & 0.00 \\
& Entrance is closed calculations & 1.31 & 1.17 & 3.04 \\
\hline
\end{tabular}




\section{Experimental Study of Pulse Cleaning System}

Investigation of the aerodynamic efficiency of the developed system cleaning was conducted on a specially designed experimental model of the reactor (see Figure 10), which preserves the basic dimensions of the real reactor.

The model of the reactor was a cylindrical tube 1 with an inner diameter of $211 \mathrm{~mm}$ and a length of $1000 \mathrm{~mm}$. At the entrance of the reactor model is hosted a unit forming an annular jet for cleaning, which consists of an annular chamber (prechamber) 7 with a volume of $0.6-0.7 \mathrm{dm}^{3}$, tubes 8 with a diameter of $16 \mathrm{~mm}$ for the air supply and slotted nozzle 9 as an annular gap formed by the inner wall of the pipe 1 and the outer wall of the input cylinder 10 . The gap width $\delta$ can vary from 2 to $12 \mathrm{~mm}$. Air supply tubes located at an angle of $45^{\circ}$ to the radius of the tube, which reduces the total pressure loss at the entrance to the prechamber and forms a twisted flow inside the reactor. To create circular pulsed jet, we use the air at room temperature (instead of oxygen under actual conditions). In the central part of the reactor input, it is a cylinder 10 with diameter of $180 \mathrm{~mm}$, through which the pulse annular jet sucked the air from the atmosphere.

As a source of pulse gas flow, a pnevmopulse generator 2 developed by the authors [10] was used. The generator consists of storage tank 3 with a volume $9.4 \mathrm{dm}^{3}$, designed for pressures up to $1.0 \mathrm{MPa}$, exhaust nozzle 4 with diameter of $41 \mathrm{~mm}$ and high-speed valve 5. Pnevmopulse generator was connected to the reactor by rubber hoses 6 of $18 \mathrm{~mm}$ in diameter and $1 \mathrm{~m}$ in a length.

To carry out the time-dependent measurements of pulse pressure at the reactor outlet special high-speed digital test equipment, which included initial pressure transducer 11, and a registration system based on PC was implemented. In each experiment, 4096 samples were recorded during $0.65 \mathrm{~s}$ with the help of 10-bit ADC. The absolute error of pressure measurements did not exceed $70 \mathrm{~Pa}$.

Experiments were carried out as follows. First of all Pitot probe with a diameter of $3 \mathrm{~mm}$ was mounted at the reactor outlet. The recording apparatus was set in a state of readiness.

Pressured air is filled storage volume 3 for 3-5 seconds until the pressure in the network, then automatically activated high-speed valve 5 (time of full opening of 3-4 ms) and a release of working gas through the slotted nozzle 4 for 50-60 ms (see Figure 11). At this time we recorded the total pressure at a given point of the outlet plane of the reactor model. A typical oscillogram of the total pressure recording is shown in Figure 12.

From each oscillogram, a section length of $100 \mathrm{~ms}$ was cut out for further analysis. It began after the arrival of the perturbation to the pressure transducer. Integral of this region was calculated during the time of the positive phase pulse from signal being recorded. Dividing the received pulse at the expiration of the time scale of the pnevmopulse generator $(60 \mathrm{~ms})$, we obtain the mean value of the total pressure in this experiment. This value is used to calculate the average speed of subsonic flow during the period in the assumption that the static flow pressure and atmospheric pressure are equal.

All experiments were performed at an initial pressure of air in generator of $0.46 \mathrm{MPa}$ and a temperature of $285 \mathrm{~K}$. At these parameters, storage chamber of pnevmopulse generator implies $0.0406 \mathrm{~kg}$ of air. Maximum flow rate at the beginning of the exhaust is $1.06 \mathrm{~kg} / \mathrm{s}$ or $0.9 \mathrm{~m}^{3} / \mathrm{s}$. Average mass flow rate during $0.060 \mathrm{~s}$ will be $0.68 \mathrm{~kg} / \mathrm{s}$ and $0.57 \mathrm{~m}^{3} / \mathrm{s}$. For comparison, that the stationary compressor providing the same air flow rate $\left(0.8 \mathrm{~m}^{3} / \mathrm{s}\right)$, has a drive power of $140 \mathrm{~kW}[11]$. High values of specific flow productivity are a distinctive feature of pulse systems and allow relatively easy to solve the problems of industrial cleaning systems from deposits.

The width of the annular gap in the experiments was $\delta=12.0,6.0$, and $2.5 \mathrm{~mm}$. According to the calculations the initial jet velocity was 66,133 , and $266 \mathrm{~m} / \mathrm{s}$ (for slots with $\delta=12 \mathrm{~mm}, 6 \mathrm{~mm}$ and $2.5 \mathrm{~mm}$, resp.). To evaluate the ability of ejecting annular jet for cleaning, experiments were carried out with open and closed section of the input cylinder 10 . The obtained profiles of mean velocity at the outlet of the reactor are shown in Figure 13. Light symbols correspond to an open entrance into a reactor, the dark to closed entrance. It is seen that at the reactor outlet air velocity is slowed down, but remains at least $30-40 \mathrm{~m} / \mathrm{s}$, which ensures the effective destruction of the deposits on the walls. In a length of $1000 \mathrm{~mm}$, there is no alignment of the flow, and the maximum velocity is near the walls. This confirms the correctness of our choice of annular injection scheme for cleaning the reactor at a specified length.

The mass of flowing air at the outlet of the reactor under different input conditions, obtained by integrating the axial velocity distribution over the area is shown in Table 1. It also shows the coefficient of ejection as the ratio of the mass of air ejected from the environment to the mass of the ejecting gas flowing from pnevmopulse generator in the form of an annular jet. We see that when the open entrance takes place a visible ejection of gas occurs, and its magnitude increases with decreasing size of the annular gap. In the experiment, the maximum ejection coefficient $(80 \%)$ provides an annular jet, which follows from the gap of $2.5 \mathrm{~mm}$. In calculating the coefficient of ejection exceeds the experimental values of 23 times and reaches $250 \%$. The gap $12 \mathrm{~mm}$ in experiment generates ejection coefficient of $35 \%$, and the calculation of up to $70 \%$. It is interesting to note that even with a closed entrance gas mass addition is observed up to $26 \%$. This indicates the presence of backflow through the central portion of the output section of the reactor, where the measurements were made with low accuracy. The presence of back flow in the central part of the output section at the closed entrance and width of the gap of $2.5 \mathrm{~mm}$ was observed visually in the experiments. In this case, the ejection is a negative factor because it implies additional disturbances in the gasdynamic flow pattern and can lead to a breach of the technological process in the reactor. From this point of view, it is preferable to use a larger gap (e.g., $12 \mathrm{~mm}$ ), which performs the task of cleaning and does not create problems with ejection. In the calculations with the swirling jet an 
ejection coefficient is further enhanced for all values of the slot heights.

In Figure 14 the values of flow velocity, referred to the velocity measured along the tube axis for open and closed entrance with gap width of $2.5 \mathrm{~mm}$ are shown. It is seen that the maximum velocity reached at the orientation of Pitot probe at an angle of $40-50^{\circ}$ to the axis in the direction of the expected tangential velocity component. Accordingly, the same direction has an absolute velocity vector of the swirling flow. It means that original angle of twist of $45^{\circ}$ has not changed over a length of $1000 \mathrm{~mm}$. Taking it into account, the values of the axial component of jet velocity, shown in Figure 13 shall be increased by $25-50 \%$, so the real value of the flow velocity relative to the tube walls reaches up to $60 \mathrm{~m} / \mathrm{s}$.

\section{Conclusion}

The results of the studies have shown that the annular pulse jet ensures the gas flow velocity (up to $60 \mathrm{~m} / \mathrm{s}$ ) sufficient to clean over the whole length of the inner wall of a chemical reactor under consideration. In accordance with the experimental and theoretical results of this study unique pulse cleaning system was designed, manufactured, and installed on a real existing chemical reactor. Experience in continuous operation showed that the system has a high cleaning efficiency and reliability, so it is possible to recommend similar cleaning systems for widespread use in the chemical industry.

\section{References}

[1] N. N. Rykalin et al., "Thermodynamics of the syntheses of the dioxide of titanium at the incineration of the tetrachloride of titanium in the oxygen," FCHOM, vol. 4, p. 53, 1977 (Russian).

[2] B. Karlemo, P. Koukkari, and J. Paloniemi, "Formation of gaseous intermediates in titanium(IV) chloride plasma oxidation," Plasma Chemistry and Plasma Processing, vol. 16, no. 1, pp. 59-77, 1996.

[3] J.-G. Li, M. Ikeda, R. Ye, Y. Moriyoshi, and T. Ishigaki, "Control of particle size and phase formation of $\mathrm{TiO}_{2}$ nanoparticles synthesized in RF induction plasma," Journal of Physics D, vol. 40, no. 8, pp. 2348-2353, 2007.

[4] A. D. Zimon, Adhesion of Dust and Powders, Khimia (Chemistry), Moscow, Russia, 1976, (Russian).

[5] N. Y. Bulatov and M. P. Sharygin, Pulse Aerodynamic Cleaning of Surfaces in Chemical Technology, Alma-Ata.Gylym, 1990, (Russian).

[6] Y. M. Shchelokov, A. M. Avvakumov, and Y. K. Sazykin, Cleaning of Heating Surfaces of Heat-Recovery Boilers, Energoatomizdat, Moscow, Russia, 1984, (Russian).

[7] E. S. Shchetinkov, Physics of Gases Combustion, Nauka (Science), Moscow, Russia, 1965, (Russian).

[8] A. A. Gurin, P. S. Maliy, and S. K. Savenko, Air Shock Waves in the Mines, Nedra (Subsoil), Moscow, Russia, 1983, (Russian).

[9] G. N. Abramovich, Applied Gas Dynamics. Part 1, Nauka (Science), Moscow, Russia, 1991, (Russian).

[10] V. I. Zvegintsev, “Claim of Russian Federation,” no. 2023228, 1992.

[11] Z. Z. Rahmilevich, Compressor Units, Khimiya (Chemistry), Moscow, Russia, 1989, (Russian). 

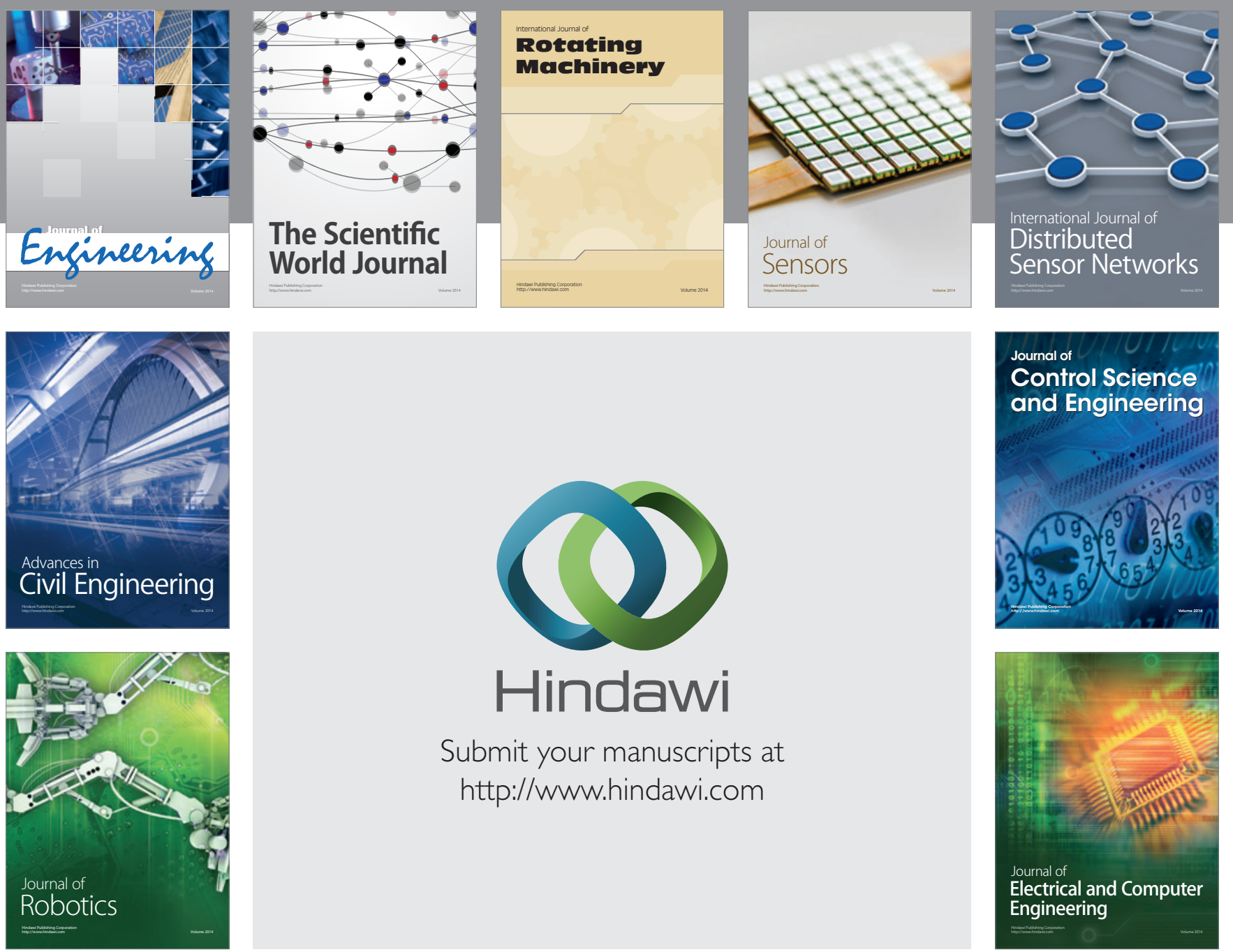

Submit your manuscripts at

http://www.hindawi.com
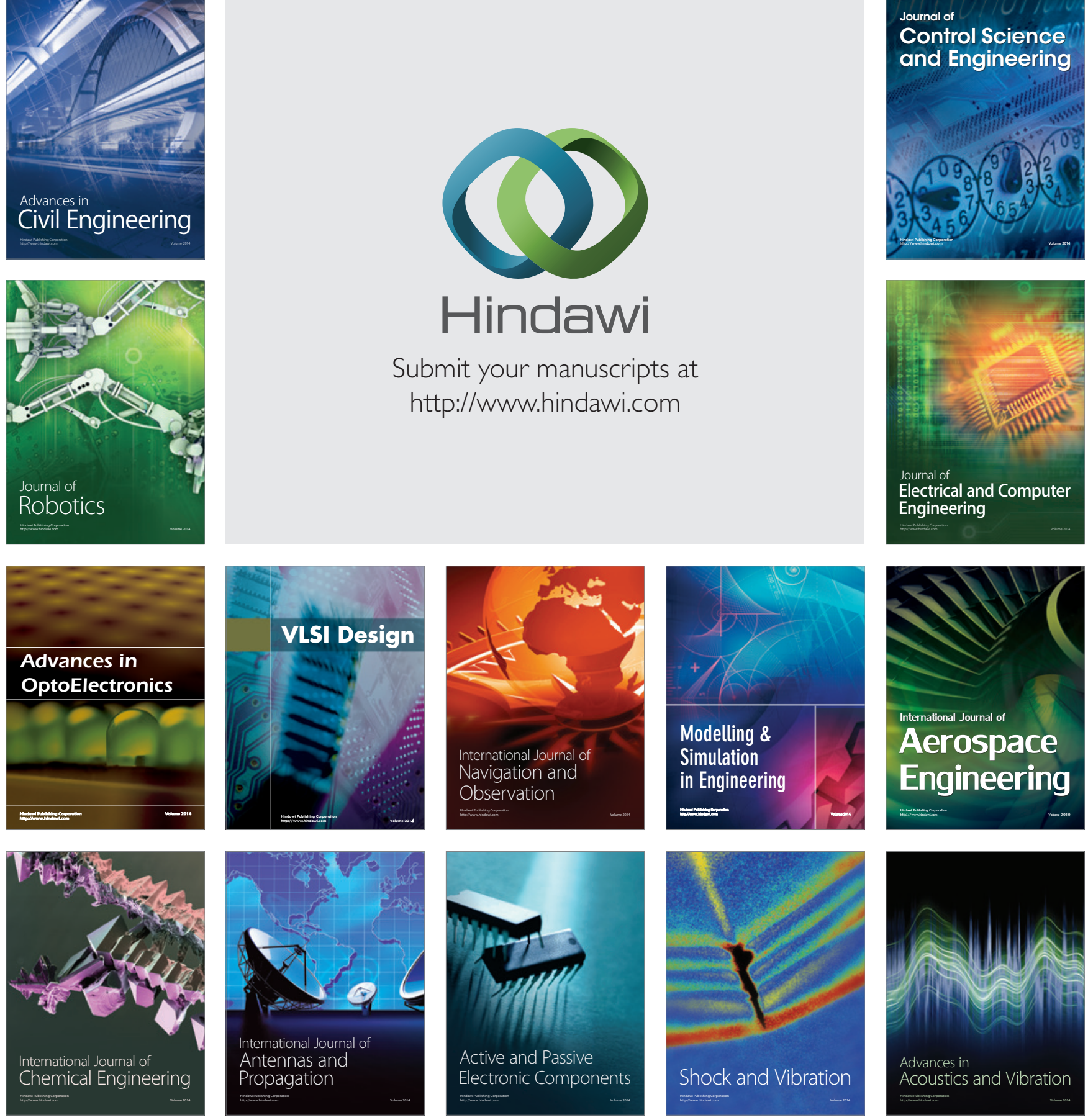